\title{
RAMAN SPECTROSCOPIC OBSERVATIONS ON THE STRUCTURAL CHARACTERISTICS AND DISSOCIATION BEHAVIOR OF METHANE HYDRATE SYNTHESIZED IN SILICA SANDS WITH VARIOUS SIZES
}

\author{
Changling Liu*, Yuguang Ye, Xunhua Zhang \\ Qingdao Institute of Marine Geology, \\ Qingdao, 266071, CHINA \\ Hailong Lu, John A. Ripmeester \\ The Steacie Institute for Molecular Sciences \\ National Research Council of Canada \\ 100 Sussex Drive, Rm 111 \\ Ottawa, Ontario, K1A OR6 \\ CANADA
}

\begin{abstract}
Raman spectroscopic observations of the characteristics and dissociation of methane hydrate were carried out on hydrates synthesized in silica sands with particle sizes of 53-75 $\mu \mathrm{m}, 90-106 \mu \mathrm{m}$, 106-150 $\mu \mathrm{m}$, and $150-180 \mu \mathrm{m}$. The results obtained indicate that methane hydrates formed in silica sands had similar characteristics regarding cage occupancy and hydration number (5.99) to bulk hydrate, indicative of no influence of particle size on hydrate composition. During hydrate dissociation, the change in average intensity ratio of large to small cages were generally consistent with that of bulk hydrate but dropped dramatically after a certain time, and this turning point seems to be related to the particle size of silica sands.
\end{abstract}

Keywords: Raman spectroscopy, methane hydrate, silica sand, cage occupancy, hydration number, dissociation behavior

\section{INTRODUCTION}

Natural gas hydrate is often taken to be a potential energy source due to the huge amount available in nature $[1,2]$. Considering the features of favorable gas hydrate reservoirs, it has been suggested that gas production from hydrate should be exploited by in situ hydrate dissociation [3]. As a result, a full understanding of hydrate decomposition in a typical reservoir setting is particularly important. The dissociation rate, which depends on $\mathrm{T}-\mathrm{P}$ and other environmental conditions, is an essential parameter for evaluating the efficiency of gas recovery from hydrate in sediment. A number of studies [4-6] have reported the dissociation rate during depressurization and thermal stimulation.
However studies of the dissociation rate by conventional methods cannot yield information on the mechanism of hydrate dissociation. For investigating the dissociation mechanism some researchers have applied X-ray CT [7, 8] and nuclear magnetic resonance (NMR) [9-11] to study the dissociation kinetics on a micro scale.

Raman spectroscopy has been widely used to study gas hydrates, with the advantage of giving information about cage occupancy in addition to the identification of the guest molecules [12]. Attempts have been made to observe $\mathrm{CH}_{4}$ hydrate decomposition using Raman spectroscopy [13-15]. The results obtained showed that gas hydrates dissociate uniformly.

\footnotetext{
*Corresponding author: Phone: 86-532-85755855 Fax: 86-532-85751905 E-mail:qdliuchangling@163.com
} 
Except for those occurring as massive deposits on the seafloor, natural gas hydrates exist in sediments and are subject to their influence. Studies of the characteristics and dissociation in sediments are important to understand hydrate formation and dissociation mechanisms in nature. Unfortunately, except for the report on the structural information of natural gas hydrates from Mallik, Mackenzie delta [16], no systematic study has been carried out on hydrate in sediment. This research reports the characteristics and dissociation of methane hydrates synthesized in silica sands of various sizes with Raman spectroscopy.

\section{EXPERIMENTS}

\section{Sample preparation}

The samples were prepared by reacting methane gas with ice, which was mixed with silica sand at a ratio $1: 1(\mathrm{v} / \mathrm{v})$, in a $500 \mathrm{~cm}^{3}$ pressure cell. The silica sand was from Sigma-Aldrich with a purity $>99 \%$, and methane gas $(>99.95 \%)$ was the product of Praxair Canada. The ice-silica sand mixture $\left(\sim 10 \mathrm{~cm}^{3}\right)$ was loaded into the cell at the temperature of dry ice $\left(-78{ }^{\circ} \mathrm{C}\right)$, then the cell was sealed and evacuated. After being charged with methane gas to $8 \mathrm{MPa}$, the cell was moved into a $20{ }^{\circ} \mathrm{C}$ freezer and left there for 1 hour, and later it was set in a $2.5^{\circ} \mathrm{C}$ water bath. When no significant pressure drop was observed for a certain period ( 2 days), the cell was placed in liquid nitrogen and opened for sample recovery. The sizes of silica sands tested are 53-75 $\mu \mathrm{m}, 90-106 \mu \mathrm{m}, 106-150$ $\mu \mathrm{m}$, and $150-180 \mu \mathrm{m}$.

\section{Raman spectroscopic observation}

The experiments were carried out with a Raman spectrometer (Acton Research Corporation, Model: Spectropro 2500i) equipped with a Witec confocal microscope and $\mathrm{Ar}^{+}$laser (SpectroPhysics Laser: Model 177G, $100 \mathrm{~mW}$ ) operating at $514.5 \mathrm{~nm}$.

The test sample was loaded into an aluminum sample holder, which was pre-cooled down to the temperature of liquid nitrogen and placed in a custom-made box with a $3 \mathrm{~cm}(\Phi)$ window covered with sapphire glass.

For studying the characteristics of methane hydrate formed in silica sands, the sample holder was cooled with liquid nitrogen throughout the experiments. Signals were collected at 4-6 positions on each sample, and the result was reported as an average.
For hydrate dissociation experiments, the box was filled with dry ice after the sample loading using a similar procedure for characterization study. As the dry ice sublimed, the temperature of the sample holder increased gradually and methane hydrate started to dissociate. The observations were taken over an interval of 2 minutes starting 3 minutes after sample loading, and the signal of each observation was co-added for 50 accumulations. The experiment ended when $\mathrm{C}-\mathrm{H}$ signals were no longer observed. Throughout the experiments, the laser was focused on a spot on the sample with a 10x lens, although the focus was adjusted at times for a better signal quality.

\section{RESULTS AND DISCUSSION \\ The characteristics of methane hydrate formed in silica sands}

Figure 1 shows the Raman spectra of methane hydrates formed in silica sands along with that of the bulk methane hydrate. Similar to that for the bulk hydrate, the signal from hydrate in silica sand has two peaks at 2902 and $2914 \mathrm{~cm}^{-1}$, representing methane molecule in large and small cages, respectively [17].

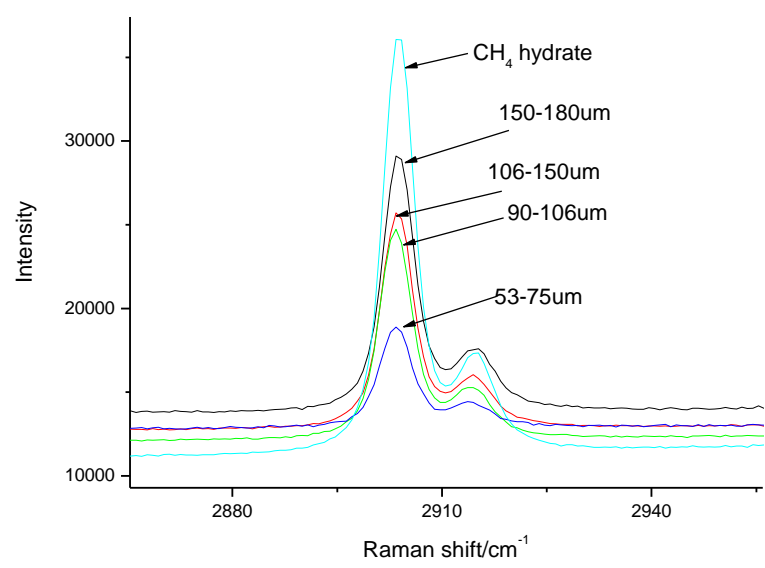

Figure 1 Raman spectra of methane hydrates synthesized in sand with various sizes.

The cage occupancies of methane molecules in large and small cages have been calculated with the method described in references $[16,17,18]$. As shown in Table 1, similar to the bulk pure methane hydrate, those formed in silica sands have occupancies of $\mathrm{CH}_{4}$ over large cage about 0.96, while the small cage occupancy of $\mathrm{CH}_{4}$ varies in a comparatively larger range (0.94-0.96) but still similar to bulk hydrate (0.95). As compared with results reported on natural samples [17, 18], the 
occupancies of $\mathrm{CH}_{4}$ over cages of hydrates synthesized in silica sands are similar to natural hydrates, the large cage being almost fully occupied and the small cage occupancy varying in a relatively wide range, probably due to the difference in formation environments. As shown in Table 1, the occupancies of $\mathrm{CH}_{4}$ in both large and small cages are independent of particle size, indicative of no influence of particle size on the structure of hydrate formed in sands.

Table 1 The characteristics of methane hydrate formed in silica sand

\begin{tabular}{|c|c|c|c|c|c|}
\hline Sample & $\begin{array}{c}\text { Sand } \\
\text { size }(\mu \mathrm{m})\end{array}$ & $\begin{array}{c}\text { Obs } \\
\#\end{array}$ & \multicolumn{2}{|c|}{ Cage occupancy } & Hydration \\
& & Small & Large & number \\
\hline \multirow{2}{*}{$\begin{array}{c}\text { Sand- } \\
\text { ice }\end{array}$} & $150-180$ & 5 & $0.961 \pm$ & $0.961 \pm$ & $5.98 \pm 0.01$ \\
& & & 0.007 & 0.003 & \\
\cline { 2 - 6 } & $106-150$ & 6 & $0.950 \pm$ & $0.964 \pm$ & $5.99 \pm 0.01$ \\
& & & 0.013 & 0.004 & \\
\cline { 2 - 5 } & $90-106$ & 5 & $0.939 \pm$ & $0.965 \pm$ & $6.00 \pm 0.01$ \\
& & & 0.031 & 0.007 & \\
\cline { 2 - 5 } & $53-75$ & 4 & $0.957 \pm$ & $0.962 \pm$ & $5.99 \pm 0.01$ \\
$\mathrm{CH}_{4}$ & - & 6 & $0.947 \pm$ & $0.965 \pm$ & $5.98 \pm 0.01$ \\
hydrate & & & 0.010 & 0.003 & \\
\hline
\end{tabular}

Estimates of the hydration number were made as well as referring to the occupancies of $\mathrm{CH}_{4}$ over hydrate cages (Table 1). The values of the hydration number of the samples studied are in agreement with those reported on synthetic and natural methane hydrate samples [17-19], 6.0.

\section{Raman spectroscopic observation of hydrate dissociation in silica sands}

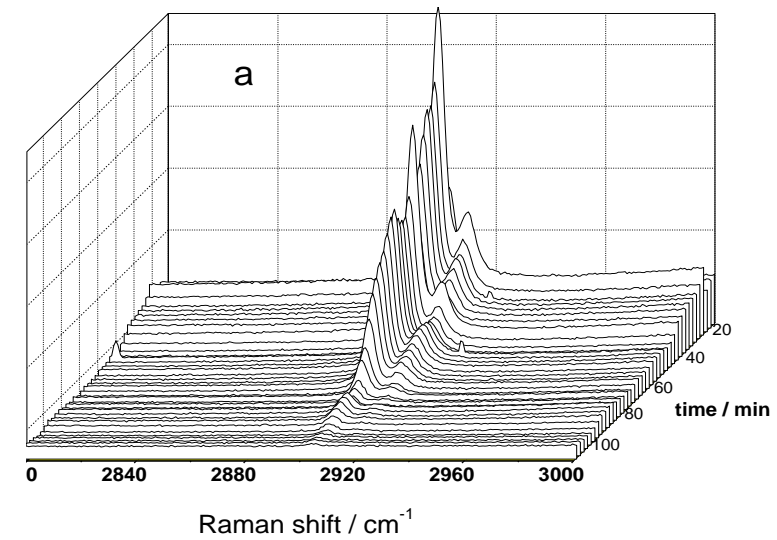

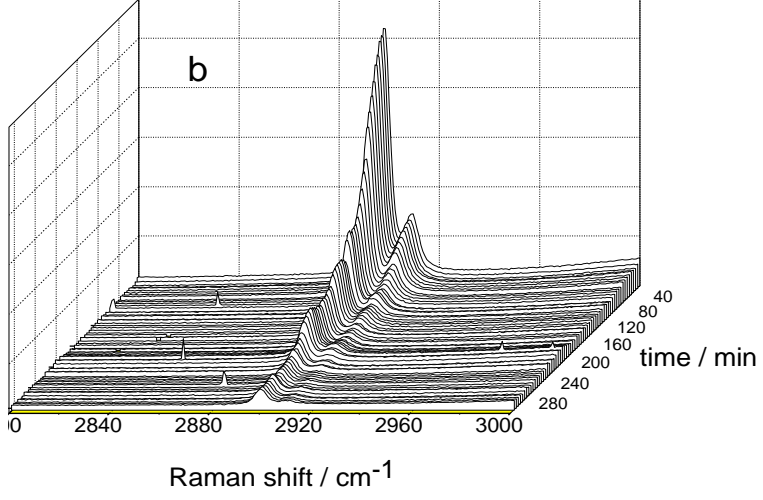

Figure 2 In-situ Raman spectroscopic observation on the dissociation process of methane hydrate in silica sands with particle size of: (a) $53-75 \mu \mathrm{m}$; and (b) in pure methane hydrate.

Figure 2 shows a representative dissociation process of methane hydrate in silica sands. It can be seen that the dissociation of methane hydrate in silica sands is similar to bulk hydrate, the intensities of both large and small cages decreasing during the course of hydrate dissociation. However, as shown in Figure 3 the intensity ratio of large cage to small cage behaved in different ways for the bulk hydrate and for that in silica sands, especially for the sands of 53-75 $\mu \mathrm{m}$ and 90-106 $\mu \mathrm{m}$. Compared with the nearly linear trend in bulk hydrate, the ratio dropped dramatically after a certain point of dissociation. Although this may suggest that in silica sands the large cage loses methane faster than the small cage, other explanations are more likely.

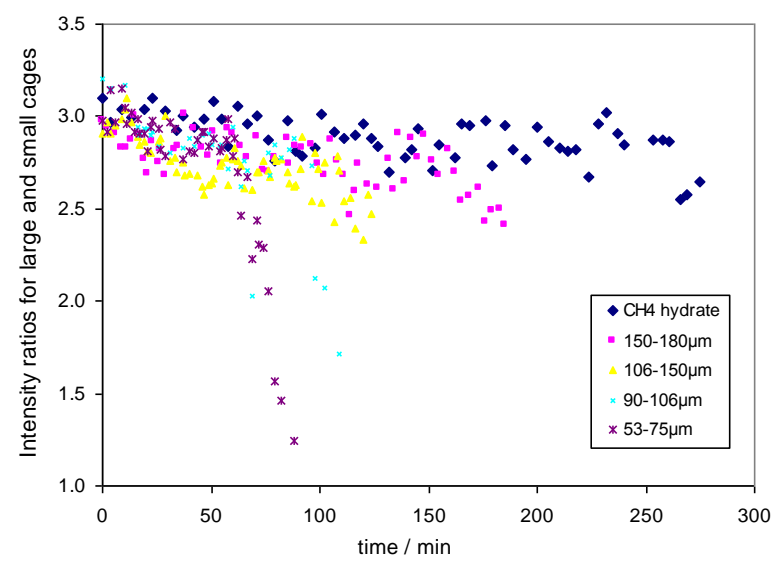

Figure 3. Variations of intensity ratios of large to small cages through hydrate dissociation in silica sands. 
Preferential disappearance of the large cage guests of gas hydrate has been reported by Dec et al. [10] for a mixed methane-ethane hydrate. It was explained as the result of the lower stability of hydrate containing exclusively ethane. Our results on bulk methane hydrate are consistent with the previously reported observation of Rovetto et al. [23] in that the unit cell decomposes as a single entity. However, for the hydrate in silica sand the timing of the dramatic drop in the ratio is particlesize dependent: it is not obvious in sands larger than $106 \mu \mathrm{m}$, and it comes earlier in the finer silica sands. For example, it was about 80 minutes after the experiment started in silica sands of 90-106 $\mu \mathrm{m}$, but only about 50 minutes for silica sands of 53-75 $\mu \mathrm{m}$. One explanation is that the nature of the hydrate changes with the pore sizes present in the silica sands and that hydrate in some pores decomposes more rapidly than hydrate in other pores.

\section{CONCLUSION}

Through studies on methane hydrates synthesized in a series of silica sands, both the characteristics and the dissociation of methane hydrate in silica sands are found to be generally similar with those in bulk methane hydrate. However, the dissociation behavior of hydrate in fine sands was found different from bulk hydrate, the average ratio of large to small cage of methane hydrates in silica sands dropped dramatically in fine sands after certain time, whereas it changed linearly with time in bulk methane hydrate.

\section{ACKNOWLEDGEMENT}

C. Liu thanks for the financial supports from the government of Shandong Province and Qingdao Institute of Marine Geology for his stay at National Research Council Canada.

\section{REFERENCES}

[1] Kvenvolden K. A. Potential effects of gas hydrate on human welfare. Proc. Natl. Acad. Sci. 1999; 96: 3420-3426.

[2] Collett T.S. Energy resource potential of natural gas hydrate. AAPG Bull. 2002; 86: 1971-1992.

[3] Ji C., Ahmadi G., Smith D.H. Natural gas production from hydrate decomposition by depressurization, Chem Eng Sci. 2001; 56: 58015814.
[4] Kono H.O., Marasimhan S., Song F., Smith D.H. Synthesis of methane gas hydrate in porous sediments and its dissociation by depressurizing. Powder Technology 2002; 122: 239-246

[5] Sun C. Y., Chen G. J. Methane hydrate dissociation above 0 and below 0. Fluid Phase Equilibria 2006; 242: 123-128

[6] Sung W., Lee H., Kim S. Experimental investigation of production behaviors of methane hydrate saturated in porous rock. Energy Sources 2003; 25: 845-856

[7] Kneafsey T., et al., Methane hydrate formation and dissociation in partially saturated sand measurements and observations, in Fifth International Conference on Gas Hydrates, 2005, Trondheim, Norway.

[8] Freifeld B.M., Kneafsey T.M. Investigating methane hydrate in sediment using $\mathrm{X}$-ray computed tomography. In C.E. Taylor and J.T. Kwan (eds.) Advances in the Study of Gas Hydrates, 227-238 (2004).

[9] Moudrakovski I.L., Ratcliffe C.I., McLaurin G.E., Simard B., and Ripmeester J. A. Hydrate layers on ice particles and superheated ice: a ${ }^{1} \mathrm{H}$ NMR microimaging study. J. Phys. Chem. A 1999; 103: 4969.

[10] Dec S. F., Bowler K. E., Stadterman L. L., Koh C. A., Sloan E. D. NMR study of methane + ethane structure I hydrate decomposition. J. Phys. Chem. A, 2007, 111: 4297-4303

[11] Gupta A., Dec S.F., Koh C.A., Sloan E.D. NMR investigation of methane hydrate dissociation. J. Phys. Chem. C. 2007; 111: 23412346

[12] Sum A. K., Burruss R. C., Sloan E. D. Jr. Measurement of Clathrate Hydrates via Raman SpectroscopyJ. Phys. Chem. B 1997; 101: 73717377

[13] Komai T., Kang S.P., Yoon J.H., Yamamoto Y., Kawamura T., Ohtake M. In Situ Raman Spectroscopy Investigation of the Dissociation of Methane Hydrate at Temperatures Just below the Ice Point. J. Phys. Chem. B 2004; 108: 8062-8068. [14] Kawamura T., Ohga K., and Higuchi K. Dissociation Behavior of Pellet-Shaped MethaneEthane Mixed Gas Hydrate Samples. Energy Fuels 2003; 17: $614-618$.

[15] Charles E.T., Dirk D.L., Niall E. Methane hydrate research at NETL: Research to make methane production from hydrates a reality. Journal of Petroleum Science and Engineering 2007; 56: 186-191.

[16] Ripmeester J. A., Lu H., Moudrakovski I., 
Dutrisac R., Wright F., and Dallimore S. Structure and composition of gas hydrate in sediment recovered from Mallik 5L-38, Mackenzie Delta, N.W.T., Canada: X-ray diffraction, Raman and solid state NMR spectroscopies, in Scientific Results from Mallik 2002 Gas Hydrate Production Research Well Program, Mackenzie Delta, Northwest Territories, Canada, edited by S. R. Dallimore and T. S. Collett, Geol. Surv. Can. Bull. 2005; 585: 106.

[17] Ripmeester J.A., Ratcliffe C.I. Lowtemperature cross-polarization/magic angle spinning 13C NMR of solid methane hydrates: Structure, cage occupancy, and hydration number. J. Phys. Chem. 1988; 92: 337-339.

[18] Lu H., Moudrakovski I., Riedel M., Spence G., Dutrisac R., Ripmeester J.A., Wright F., Dallimore S. Occurrence and structural characterization of gas hydrates association with a cold vent field, offshore Vancouver Island. J. Geophys. Res. 2005; 110: B10204, doi:10.1029/2005JB003900.

[19] Uchida T., Hirano T., Ebinuma T., Narita H., Gohara K., Mae S., Matsumoto R. Raman spectroscopic determination of hydration number of methane hydrates. AIChE J. 1999; 45: 26412645.

[20] Rovetto L.J., Bowler K.E., Stadterman L.L., Dec S.F., Koh C.A. and Sloan E.D. Dissociation studies of $\mathrm{CH}-\mathrm{CH}$ and $\mathrm{CH}-\mathrm{CO}$ binary gas hydrates. Fluid Phase Equilibria 2007; 261: 407-413. 